\title{
THE
}

\section{Large Pyroelectric Response from Reactively Sputtered Aluminum Nitride Thin Films}

\author{
Everett E. Crisman \\ John S. Derov \\ Alvin J. Drehman \\ Otto J. Gregory \\ University of Rhode Island, ogregory@uri.edu
}

Follow this and additional works at: https://digitalcommons.uri.edu/che_facpubs

Part of the Chemical Engineering Commons

Terms of Use

All rights reserved under copyright.

\section{Citation/Publisher Attribution}

Chrisman, E. E., Derov, J. S., Drehman, A. J., \& Gregory, O. J. (2005). Large Pyroelectric Response From Reactively Sputtered Aluminum Nitride Thin Films. Electrochemical and Solid State Letters, 8(3), H31-H32. doi: 10.1149/1.1857742

Available at: http://dx.doi.org/10.1149/1.1857742

This Article is brought to you for free and open access by the Chemical Engineering at DigitalCommons@URI. It has been accepted for inclusion in Chemical Engineering Faculty Publications by an authorized administrator of DigitalCommons@URI. For more information, please contact digitalcommons-group@uri.edu. 


\section{Large Pyroelectric Response from Reactively Sputtered Aluminum Nitride Thin Films}

Everett E. Crisman, John S. Derov, Alvin J. Drehman and Otto J. Gregory

Electrochem. Solid-State Lett. 2005, Volume 8, Issue 3, Pages H31-H32.

doi: $10.1149 / 1.1857742$

Email alerting

Receive free email alerts when new articles cite this article - sign up in the box at the service top right corner of the article or click here

To subscribe to Electrochemical and Solid-State Letters go to:

http://esl.ecsdl.org/subscriptions

(C) 2005 ECS - The Electrochemical Society 


\title{
Large Pyroelectric Response from Reactively Sputtered Aluminum Nitride Thin Films
}

\author{
Everett E. Crisman, ${ }^{\mathrm{a}, \mathrm{z}}$ John S. Derov, ${ }^{\mathrm{a}}$ Alvin J. Drehman, ${ }^{\mathrm{a}}$ and Otto J. Gregory ${ }^{\mathrm{b}}$ \\ ${ }^{a}$ Air Force Research Laboratory, Hanscom AFB, Massachusetts 01731, USA \\ ${ }^{b}$ Department of Chemical Engineering, University of Rhode Island, Kingston, Rhode Island 02881, USA
}

We report the pyroelectric response of c-axis oriented, undoped, wurtzite, aluminum nitride reactively sputtered onto polished silicon wafers. The voltage between a metallic contact on the AlN surface and the $\mathrm{n}^{+}$-doped silicon substrate was monitored during pulsed infrared, radiant heating. From analysis of the data, a pyroelectric voltage coefficient, $\mathrm{P}_{\mathrm{V}}$, in excess of $0.5 \times 10^{6} \mathrm{~V} / \mathrm{m} / \mathrm{K}$ was extracted for films in the 600 to $2500 \AA$ thickness range.

(c) 2005 The Electrochemical Society. [DOI: 10.1149/1.1857742] All rights reserved.

Manuscript submitted August 18, 2004; revised manuscript received October 21, 2004. Available electronically January 27, 2005.

Since the demonstration of high-efficiency group-III nitride (III-N) light emitting diodes (LEDs) in $1995^{1}$ this class of compounds has found many other applications in areas as diverse as UV transparent windows and piezoelectric transducers. ${ }^{2-4}$ Because of their wurtzite structures the III-N compounds have also been suggested as possible candidates for pyroelectric (PE) sensors. Calculations by Bernardini et al. ${ }^{5}$ and Zoroddu et al. ${ }^{6}$ have predicted that III-N compounds should have significantly higher piezoelectric constants and pyroelectric coefficients 5-20 times higher than other III-V and II-VI compounds.

Subsequently, Shure et al. ${ }^{7}$ calculated that GaN could have a pyroelectric voltage coefficient of $0.7 \times 10^{6} \mathrm{~V} / \mathrm{m}-\mathrm{K} ; 40 \%$ greater than $\mathrm{LiTaO}_{3}$, the best-known high-temperature pyroelectric material. ${ }^{8}$ Recently Bykhovski et al. ${ }^{9}$ reported experimental observations of pyroelectric response in thin films of gallium nitride that were $\sim 10^{4} \mathrm{~V} / \mathrm{m}-\mathrm{K}$. Because AlN has larger piezoelectric coefficients than $\mathrm{GaN}$, it is reasonable to expect, as suggested in Ref. 2 and 7, that the pyroelectric effect might be higher in AlN. There are several immediate and potential advantages of AlN over traditional pyroelectric materials. Reactively sputtered AlN has a lower dielectric constant than current commercial PE materials ${ }^{8,10}$ and the AIN dielectric constant is relatively temperature insensitive to at least $300^{\circ} \mathrm{C}^{11}$ The thermal conductivity of AlN is on the order of 100 times higher than traditional PE materials, even at $300^{\circ} \mathrm{C}^{8,12}$ Low dielectric constant and high thermal conductivity are important for fast detector array response operation. Although a Curie temperature has not been established for the PE effect in AIN (it has been estimated at $>300^{\circ} \mathrm{C}$ for $\left.\mathrm{GaN}\right),{ }^{7}$ the group III-nitrides in general are high decomposition materials $(>1300 \mathrm{~K})^{13}$ and therefore have a potential to perform at elevated temperatures. Aluminum nitride in particular tends to survive at elevated temperatures, even in oxidizing atmospheres, due to the formation of stable aluminum oxide compounds. $^{14}$

\section{Experimental}

In this study we measured the PE voltage response of thin films of AlN prepared by dc reactive sputtering of aluminum in a $3 \times 10^{-3}$ Torr ammonia atmosphere. The power density at the target was $\sim 5 \mathrm{~W} / \mathrm{cm}^{2}$. The substrates were $0.1 \Omega$-cm, n-type, polished silicon wafers with (111) orientation. The substrates were rinsed in hot acetone, methanol, and DI water, etched in electronic grade buffered HF acid, rinsed in DI water, and dried in a zero grade nitrogen stream. Prior to the sputter deposition, the substrates were heated in situ above $200^{\circ} \mathrm{C}$ and cooled below $50^{\circ} \mathrm{C}$ while the chamber was at or below $5 \times 10^{-8}$ Torr. From X-ray diffraction $(\mathrm{XRD})$ patterns the AlN films were determined to be highly disordered with a broad peak corresponding to the d-spacing of the (0002) reflection, which is oriented normal to the substrate surface. Neither the XRD patterns

z E-mail: everett.crisman@hanscom.af.mil nor ESCA profiles of the AIN layer showed any sign of free aluminum, implying that the films were essentially stoichiometric. Hot probe measurements showed the films to be semi-insulating to slightly p-type with typical through-film resistance of $25 \mathrm{M} \Omega / \mu \mathrm{m}$ for $1 \mathrm{~cm}^{2}$ of area. The thickness of films varied from 540 to $2500 \AA \pm 50 \AA$ controlled by sputtering time. Subsequent to the AlN deposition, a 100-200 $\AA$ layer of $\mathrm{NiCr}$ was applied, by radiofrequency (RF) magnetron sputtering in argon, to act as both a contact to the AlN and to increase absorbance at IR wavelengths. The n-type silicon substrate was used as the back contact. To measure the PE response, a broadband IR source was focused onto the specimen after passing through a vane chopper. An undoped silicon wafer, etched and polished on both sides, was interposed between the source and the specimen to remove any light of frequency above the band gap of silicon and, thereby, suppress photovoltaic responses associated with substrate absorption.

\section{Results and Discussion}

The voltage response to the chopped IR source is shown in Fig. 1 for one of the specimens. As expected for a pyroelectric material, the AlN film responded to the time rate of change of temperature $(\mathrm{dT} / \mathrm{dt})$ rather than to the absolute value of temperature difference per se. A first estimate of response time can be obtained from the exponential decay part of the trace. The relaxation after the initial rise was fitted to an exponential as shown in Fig. 2, from which a 1/e response time of $0.013 \mathrm{~s}$ is calculated. By assuming a rise in temperature linearly proportional to the rate of energy input and an exponential fall in temperature proportional to the thermal conductivity of the AlN and Si substrate, then the time to reach the maximum rate of temperature change is $0.011 \mathrm{~s}$, which is close to the $0.0067 \mathrm{~s}$ to reach the maximum output voltage. The relationship used to determine $\mathrm{P}_{\mathrm{V}}$ is (see, for example, Ref. 8, p. 94)

$$
\frac{\Delta \mathrm{V}}{\Delta \mathrm{t}}=\mathrm{P}_{\mathrm{V}} \mathrm{h} \frac{\Delta \mathrm{T}}{\Delta \mathrm{t}}
$$

where $\mathrm{V}$ is the measured voltage, $\mathrm{T}(\mathrm{K})$ is the calculated temperature, $\mathrm{t}(\mathrm{s})$ is the time, and $\mathrm{h}$ is the layer thickness; $600 \AA$ for this specimen.

Both $\Delta \mathrm{V} / \Delta \mathrm{t}$ and $\Delta \mathrm{T} / \Delta \mathrm{t}$ are obtained from analysis of the Fig. 2, and a pyroelectric voltage coefficient of $\mathrm{P}_{\mathrm{V}}=0.51-0.69 \times 10^{6}$ $\mathrm{V} / \mathrm{m}-\mathrm{K}$ was extracted for this particular $600 \AA$ thick AlN layer. The range for $\mathrm{P}_{\mathrm{V}}$ depends on how one chooses the time range for calculating $\Delta \mathrm{V} / \Delta \mathrm{t}$ and $\Delta \mathrm{T} / \Delta \mathrm{t}$. The thermal responses, shown on the figure, were constructed using material properties values from the literature and a commercial finite difference heat flow calculation program. ${ }^{\mathrm{c}}$ In Fig. 3 the response to a shuttered IR pulse is shown for a complete cycle. In that figure the peak voltage for the $2500 \AA$ thick specimen is $71.6 \mathrm{mV}$. There is a residual output, $\mathrm{V}_{0}=7.5 \mathrm{mV}$,

c The modeling program used for this project was E-Z Thermal available from GK Solutions, 1606 Slate Run Circle NE, Canton, OH 44721, (330) 499-3410. 


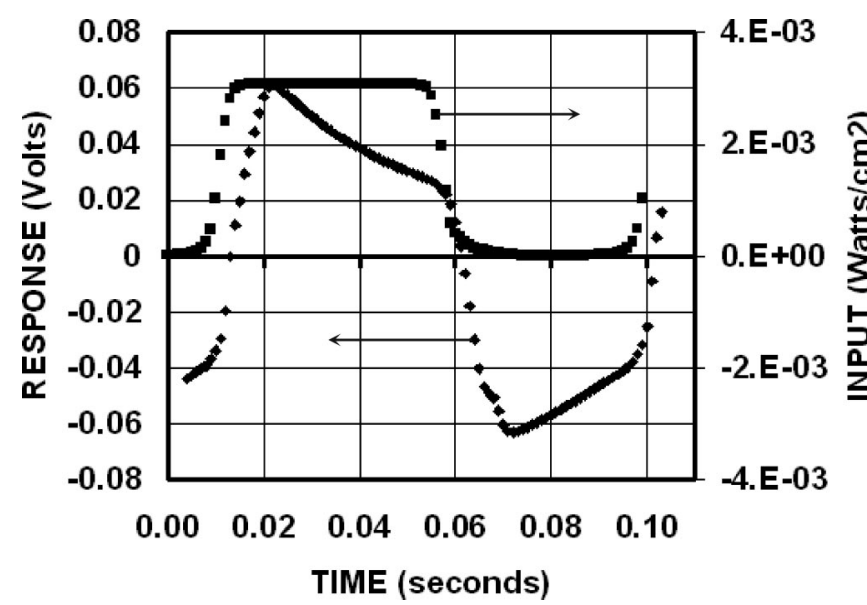

Figure 1. Response of AlN film ( ) to a pulsed, broad band, IR light source (ם) of $\sim 900 \mathrm{~K}$ color temperature. The chopping frequency was $11 \mathrm{~Hz}$ and the incident power density was $3.1 \pm 0.05 \mathrm{~mW} / \mathrm{cm}^{2}$, measured at the specimen.

during the illuminated part of the cycle which is due to the finite continuous heat flux through the film because of the difference in absolute temperature of its two sides. ${ }^{8}$

In summary, AlN appears to have a PE voltage response comparable to values found for materials used for commercial detectors ${ }^{8}$ and greater than that thus far reported for GaN. The crystal symmetry of both AlN and GaN, however, are quite high and so such large $\mathrm{PE}$ values are not expected for these compounds. Indeed, Fuflyigin et al. ${ }^{15}$ measured an AIN PE charge coefficient of $\mathrm{P}_{\mathrm{Q}}=6-8$ $\mu \mathrm{C} /\left(\mathrm{m}^{2} \mathrm{~K}\right)$, which is at least two orders lower than typical for commercial PE materials. Assuming a relative dielectric constant for AlN of $\kappa=8.5,{ }^{10}$ the $\mathrm{P}_{\mathrm{Q}}$ above converts to a PE voltage coefficient



Figure 2. The data from the positive response half cycle of Fig. $1(\downarrow)$ is compared to the calculated rate of temperature change, dT/dt ( $)$, from the heat transfer model. The intersection of the extrapolations occurs at $0.0067 \mathrm{~s}$ and $66 \mathrm{mV}$. The dT/dt curve has a maximum of $297 \mathrm{~K} / \mathrm{s}$ at $0.011 \mathrm{~s}$.

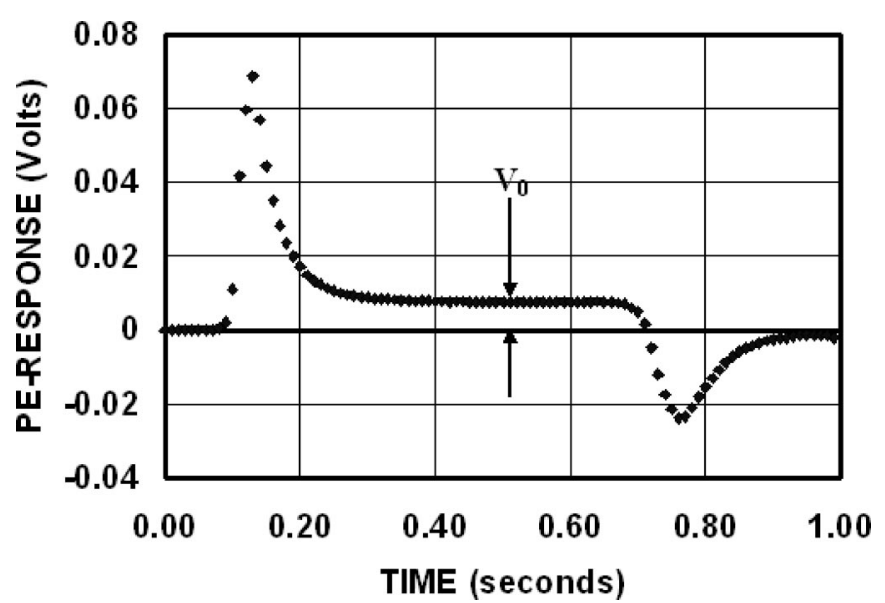

Figure 3. Response of AlN pyroelectric specimen to a shuttered pulse of 0.6 $\mathrm{s}$ duration. The maximum voltage is $0.0716 \mathrm{~V}$ occurring $0.044 \mathrm{~s}$ after the imitation of the thermal pulse. The residual voltage, $\mathrm{V}_{0}$, is $0.0075 \mathrm{~V}$.

of $\mathrm{P}_{\mathrm{V}}=0.008-0.01 \times 10^{6} \mathrm{~V} / \mathrm{m}-\mathrm{K}$, a factor of 50 lower than we calculate from our measurements. This suggests that there may be other factors such as surface oxidation, deposition related strain, unintentional incorporation of impurities, etc. that might be ultimately responsible for the measured effects. Several groups have calculated the importance of strain doping in the performance of III-N compounds. ${ }^{16,17}$ Oxygen, for instance, is known to be present in these specimens, at least at the two surfaces of the AlN layer. Additional experiments are under way to evaluate this possibility and to maximize the PE effect in thin layers of AlN.

\section{Acknowledgments}

The authors thank Kurt Kneidel and Greg Rush of GK-Solutions, Inc. for their help with the thermal modeling used in this research.

The Air Force Research Laboratory assisted in meeting the publication costs of this article.

\section{References}

1. S. Nakamura, J. Vac. Sci. Technol. A, 13, 705 (1995).

2. Ambacher, J. Phys. D, 31, 2653 (1998)

3. S. N. Mohammad, A. A. Salvador, and H. Morkoc, Proc. IEEE, 83, 1306 (1995).

4. K. M. Lakin, G. R. Kline, R. S. Ketcham, J. T. Martin, and K. T. McKarron, in Proceedings of the 43rd Annual Symposium on Frequency Control, p. 536 (1989).

5. F. Bernardini, V. Fiorentini, and D. Vanderbilt, Phys. Rev. B, 56, R10024 (1997).

6. A. Zoroddu, F. Bernardini, P. Ruggerone, and V. Fiorentini, Phys. Rev. B, 64, 45208 (2001).

7. M. S. Shure, A. D. Bykhovski, and R. Gaska, Paper presented at the MRS Fall Meeting (1998)

8. J. Fraden, AIP Handbook of Modern Sensors, Physics, Design and Applications, p. 97, AIP, New York (1993).

9. A. D. Bykhovski, V. V. Kaminski, M. S. Shur, Q. C. Chen, and M. A. Khan, Appl. Phys. Lett., 69, 3254 (1996).

10. J. G. Gualieri, J. A. Kosinski, and A. Ballato, IEEE Trans. Ultrason. Ferroelectr. Freq. Control, 41, 53 (1994).

11. A. J. Noreika, M. H. Francomb, and S. A. Zeitman, J. Vac. Sci. Technol., 6, 194 (1969).

12. G. A. Slack, R. A. Tanzilli, R. O. Pohl, and J. W. Vandersande, J. Phys. Chem. Solids, 48, 641 (1987).

13. Properties of Group III Nitrides, J. H. Edgar, Editor, INSPEC, The Institution of Electrical Engineering, London (1994).

14. L. M. Jones and M. G. Nicholas, J. Mater. Sci. Lett., 8, 265 (1989).

15. V. Fuflyigin, E. Salley, A. Osinsky, and P. Norris, Appl. Phys. Lett., 77, 3075 (2000).

16. M. S. Shure and M. A. Khan, Mater. Res. Bull., 22, 44 (1997).

17. N. Maeda, T. Nishida, N. Kobayashi, and M. Tomizawa, Appl. Phys. Lett., 73, 1853 (1998). 